\title{
LA CRISIS DEL COMANDO EN EL CINE NORTEAMERICANO DE GUERRA SUBMARINA EN LOS PERÍODOS DE POSGUERRA: LOS CASOS DE RUN SILENT RUN DEEP (ROBERT WISE, 1958) Y CRIMSON TIDE (TONY SCOTT, 1995)
}

\author{
Francisco Trujillo García-Ramos \\ Universidad de La Laguna
}

\section{RESUMEN}

La crisis del comando como argumento ha sido empleada en muchas referencias del cine de género bélico a lo largo de los años, pero es en las historias enmarcadas bajo la superficie del mar donde puede alcanzar mayor capacidad de desestabilización. Las películas del subgénero propuestas para ejemplificar este estudio son las norteamericanas Run Silent Run Deep (Robert Wise, 1958) y Crimson Tide (Tony Scott, 1995). Ambos filmes fueron producidos durante períodos de posguerra y narran la rivalidad de un comandante y su primer oficial en submarinos de la Marina de Guerra de los Estados Unidos en tiempo de guerra. Estos problemas de gobierno repercuten gravemente en el ecosistema de los navíos, generando una lucha por el control durante las patrullas. Mediante la observación de la muestra se examinará la relación de estas películas con la historia, así como las estrategias y procesos narrativos con el objetivo de verificar claves en el uso del relato.

Palabras clave: cine, Estados Unidos, Marina, guerra, submarino, comando, crisis.

THE COMMAND CRISIS IN NORTH AMERICAN SUBMARINE WAR CINEMA

IN THE POST-WAR PERIODS: RUN SILENT RUN DEEP (ROBERT WISE, 1958)

AND CRIMSON TIDE (TONY SCOTT, 1995) PROPOSALS

\section{Abstract}

The command crisis as a story line has been used in many references of the cinema war genre throughout years, but it is in the stories framed under the surface of the sea where it can reach its greatest destabilization capacity. The films of the subgenre suggested to exemplify this study are the North American Run Silent Run Deep (Robert Wise, 1958) and Crimson Tide (Tony Scott, 1995). Both films were produced during a post-war era and narrate the rivalry of a commander and his executive officer in wartime submarines of the United States Navy. Commanding problems severely affect the ecosystem of the ships, creating a struggle for control during patrol. By means of observation, the relationship between History and these films will be analysed, as much as the strategy and narrative process with the objective of verifying keys in the use of the plot.

KeYwords: cinema, United States, Navy, war, submarine, command, crisis.

DOI: https://doi.org/10.25145/j.latente.2021.19.03

Revista Latente, 19; noviembre 2021, pp. 45-72; ISSN: e-2386-8503 


\section{INTRODUCCIÓN}

El cine de guerra submarina es una subdivisión dentro del género bélico y se caracteriza por situar el escenario del drama en un entorno hostil, donde la tripulación de uno o más submarinos militares entra en combate con el enemigo bajo la superficie del mar o sobre ella. El subgénero comparte ciertas líneas temáticas con el correspondiente al de combate de naval, pero presenta una serie de singularidades que lo caracterizan de forma diferenciada. Algunos de los modelos semánticos y estructurales que las películas de guerra submarina tratan regularmente son, entre otros, la figura emblemática del padre-capitán, el confinamiento de una tripulación homosocial, la atmósfera de domesticidad, el particular uso del sonido, la ausencia de violencia gráfica en combate o el suspense en la puesta en escena (Koldau 2012: 104-109). Otras consideraciones también señalan el marcado carácter hermenéutico de las películas submarinas, que manifiesta "signos y significados constantemente» ${ }^{1}$ y un «profundo interés por la cuestión de la muerte, mucho más acentuado que en el western o la película bélica» ${ }^{2}$ (Nichols 2009: 102).

Como el resto de películas bélicas, el cine de guerra submarina se caracteriza por construirse generalmente sobre bases históricas. Ello implica la problemática de la interpretación del hecho real y la parcialidad en el punto de vista, ya que tanto sus protagonistas como los antagonistas normalmente representan a determinadas fuerzas armadas reales. Por lo tanto, se debe tener en cuenta que el modelo cultural de cada nación tiene su propia visión de la guerra (Rodríguez 2006: 164). De hecho, en un orden más amplio de la cuestión, el cine entendido como fuente para la historia ha necesitado mucho tiempo para ser considerado un documento válido en la investigación académica (Ferro 1995: 15). Esto contrasta con su enorme popularidad, que lo ha establecido como la principal fuente de consumo del hecho histórico (Rosentone 1988: 1174).

Para este estudio se han seleccionado dos películas norteamericanas realizadas durante períodos de posguerra como muestra de referencia y, a continuación, se han observado las particularidades en la representación de los escenarios de crisis del comando.

Run Silent Run Deep (Robert Wise, 1958) y Crimson Tide (Tony Scott, 1995) son dos dramas bélicos que tratan sobre la ruptura entre el comandante y el primer oficial de una misma nave en un contexto de guerra. Ambas películas son historias de ficción. En el caso de Run Silent Run Deep, se trata de cine de época, es decir, representa hechos ficticios basados en un contexto real: el desempeño del servicio de submarinistas de la Marina de los Estados Unidos durante la Guerra del Pacífico. La película está basada en la novela homónima de Edward L. Beach Jr. (1918-2002),

${ }^{1}$ Por ejemplo, la instrumentación de la sala de control del submarino, el procedimiento técnico del disparo de torpedos o el uso del sónar.

2 El entorno submarino es siempre indiferente e «inalterable»; la supervivencia o la muerte no cambiará ni conquistará el océano. Este asunto también se aborda en el filme bélico naval Cruel Sea (Charles Frend, 1953). 
un condecorado oficial de la flota de submarinos de la Segunda Guerra Mundial y posterior autor de best sellers de combate naval. Esta fue la primera novela de su autor y también la más exitosa desde su publicación en 1955. Poco después, John Gay realizaría una adaptación libre del argumento para la productora cinematográfica Hecht-Hill-Lancaster. L. Beach, decepcionado con el resultado, dejó testimonio en una entrevista posterior al estreno de la película, de que la adaptación «no era fiel a su experiencia en la Marina» (Rayner 2007: 110). El reparto, encabezado por el dúo de estrellas de Hollywood Clark Gable y Burt Lancaster, se puso al servicio del realizador Robert Wise.

Wise inició su carrera como técnico de sonido y montador $^{3}$ durante la década de 1930 para la RKO Pictures. Posteriormente, y ya como director, filmaría algunas de las películas más exitosas de Hollywood en la década de los 60, como las oscarizadas West Side Story (1961) o The Sound of Music (1965). La filmografía de Wise llama especialmente la atención por su eclecticismo. El cineasta trabajó desde el cine de guerra submarina de Run Silent Run Deep (1958), alternando a un relato ubicado en un buque de guerra de superficie en The Sand Pebbles (1966), al cine de terror, la ciencia ficción o el género musical. Wise conseguiría incidir en la cultura popular notablemente con sus éxitos, algunos de ellos considerados hoy «clásicos del cine». El propio cineasta recapituló sobre la notable diversidad de su trabajo durante una entrevista en 1998:

I've been accused by some of the more esoteric critics of not having a style, and my answer to that always is this: I've done every genre there is, and I approach each genre in the cinematic style that I think is appropriate and right for that genre. I would no more have done The Sound of Music in the thinking and approach that I did in I Want to Live! for anything. So that's why I don't have a singular mark but I justify that by saying that it's just because of the number of genres I've done and the cinematic style that's proper for each one (Institute of International Studies, UC Berkeley 1998).

Run Silent Run Deep contó con el asesoramiento técnico del contralmirante Rob Roy McGregor ${ }^{4}$, un hombre con experiencia de gobierno en dos submarinos de Clase Gato de la flota norteamericana (USS Grouper y USS Sea Cat) en la Segunda Guerra Mundial. La producción se realizó en una de las décadas de mayor popularidad para este subgénero en Estados Unidos. Del mismo período también son Submarine Command (John Farrow, 1951), Operation Pacific (George Waggner, 1951), Torpedo Alley (Lew Landers, 1952) o The Enemy Below (Dick Powell, 1957), entre otras referencias. Estas películas homenajean en formato retrospectivo el esfuerzo

${ }^{3}$ Diez años después sería nominado al premio Óscar de la Academia (AMPAS) por su trabajo en el innovador montaje de Citizen Kane (Orson Welles, 1941).

${ }^{4}$ El cierre de la película muestra el siguiente epígrafe en pantalla: «Our appreciation to the Department of Defense, The United States Navy, and the officers and men of Submarine Flotilla 1 for the cooperation extended». 
de la Marina para lograr el éxito en el Pacífico, que, muy consciente de la estrategia para consolidar su buen servicio mediante el poder comunicador del cine, accedió a prestar sus submarinos a los estudios de Hollywood ${ }^{5}$. La temática de la crisis del comando en algunos de estos filmes no evitó la condescendiente colaboración de las fuerzas armadas con los estudios durante este período de posguerra. En cualquier caso, tal y como se aborda en un apartado posterior de este artículo, estos relatos de crisis normalmente concluyen con una restauración de la buena imagen de la Marina (Rayner 2007: 114).

Run Silent Run Deep tuvo éxito en la taquilla ingresando un total de 3 millones de dólares de la época durante sus primeros 7 meses de exhibición en Estados Unidos (Lantern 2021).

Crimson Tide, realizada casi cuarenta años después del filme de Wise, es una historia original escrita por Michael Schiffer y el novelista de thrillers navales Richard P. Henrick. También es conocida la participación no oficial del cineasta Quentin Tarantino en el proceso de reescritura de la película (Internet Movie Database 2021). El contexto del relato es de ficción en la era post Guerra Fría y trata sobre la batalla que los Estados Unidos libran contra hipotéticos adversarios radicales de la República Rusa. La cinta fue producida por Don Simpson y Jerry Bluckheimer, exitoso dúo de Hollywood en las décadas de 1980 y 1990. Algunas de sus películas fueron grandes éxitos en la taquilla mundial, como Flashdance (Adrian Lyne, 1983) o Beverly Hills Cop (Martin Brest, 1984). Para Crimson Tide, Simpson y Bluckheimer contrataron a Tony Scott como realizador. Scott ya era muy reconocido por sus éxitos en publicidad y en el género del cine de acción. El estilo vibrante, moderno e hiperbólico en la puesta en escena del director había revolucionado pocos años antes el imaginario visual de la Fuerza Aérea de los Estados Unidos en otra película bélica del dúo Simpson-Bluckheimer: Top Gun (Tony Scott, 1986).

Crimson Tide inició su producción en 1993, pocos años después del éxito de otro filme de guerra submarina en el contexto de la Guerra Fría: The Hunt for Red October (John McTiernan, 1990), que obtuvo una recaudación de más de 200 millones de dólares en la taquilla internacional (Box Office Mojo 2020), y supuso para una audiencia moderna un revival del subgénero, ahora localizado en los avanzados submarinos nucleares estratégicos. No obstante, Crimson Tide no contó con el asesoramiento y participación de la Marina de los Estados Unidos durante su producción, al contrario que la película de McTiernan. La Armada rechazó el argumento del motín en un submarino norteamericano contemporáneo y decidió no colaborar con la producción (Suid 2002: 748). Crimson Tide no parecía que estuviese destinada a ser el eficaz instrumento de propaganda que sí resultó ser Top Gun. Tras el

5 En beneficio de ello, muchas películas de guerra submarina de la época tienen excelentes tomas exteriores de los auténticos navíos. Hoy en día se recurre habitualmente a las imágenes generadas por ordenador (CGI) para recrear estos submarinos en la pantalla con resultados de un realismo discutible. 
éxito de esta película, el aumento de cifras en los alistamientos para la Fuerza Aérea de los Estados Unidos se estimó en un 500 por ciento (Robb 2004: 182).

Una vez comenzado el rodaje, el equipo de fotografía realizó tomas aéreas exteriores del auténtico USS Alabama abandonando el puerto en Pearl Harbor sin prevenir al buque ni contar con permiso expreso. No obstante, la filmación pudo llevarse a cabo, ya que es acorde a la ley norteamericana grabar y difundir imágenes de una nave militar en espacio público (Ryan 1995). El material de ese día puede verse durante la escena en la que el Alabama zarpa y poco después se sumerge al comienzo de la película. Por el contrario, la Marina Nacional francesa sí colaboró con la producción, y se rodaron varias tomas en el portaaviones Foch (R-99) empleadas en la escena del noticiario de los primeros minutos de la película.

Crimson Tide se rodó pocos años después del fin de la Guerra Fría. Las relaciones entre los Estados Unidos y la nueva Federación Rusa se habían encauzado, aunque en Moscú se vivían tiempos muy inestables de crisis institucional, agravada por los extraordinarios sucesos del Octubre Negro en 1993. La película de Tony Scott interpretó esta realidad virándola hacia un relato de guerra con una hipotética oposición radical de la nueva república.

Crimson Tide fue un éxito en la taquilla internacional el verano de su estreno en 1995, con una recaudación que alcanzó la cifra de 157 millones de dólares (Box Office Mojo 2020). La película ha sido editada en múltiples formatos domésticos desde su estreno en las salas, y tampoco ha dejado emitirse por canales de televisión desde entonces. Actualmente, es considerada uno de los 5 filmes más populares de todos los tiempos dentro del subgénero de guerra submarina en el portal web IMDB (Internet Movie Database 2021).

Durante una entrevista concedida pocos ańos antes de su muerte en 2012, Tony Scott dejó testimonio de la relación de su filmografía con la consolidación popular de los denominados «clásicos del cine»:

I always get criticized for style over content, unlike Ridley's [Scott] films like Alien, Blade Runner or Gladiator that go right into the classic box right away. Mine sort of hover. Maybe with time people will start saying they should be classics, but I think I'm always perceived as reaching too hard for difference, and difference doesn't categorize you as the «classic» category (Cinema Blend 2009).

Al contrario que Wise, Scott recapitula sobre la crítica recibida por su énfasis en la estética en detrimento del contenido. Cabe destacar que ambas películas de la muestra coexisten en una escena durante el primer acto de Crimson Tide: el momento está protagonizado por dos oficiales que charlan animadamente sobre cine de guerra submarina y se cita, entre otras, a Run Silent Run Deep. De esta manera, la película de Scott cataloga al filme de Wise como un clásico dentro del subgénero. 


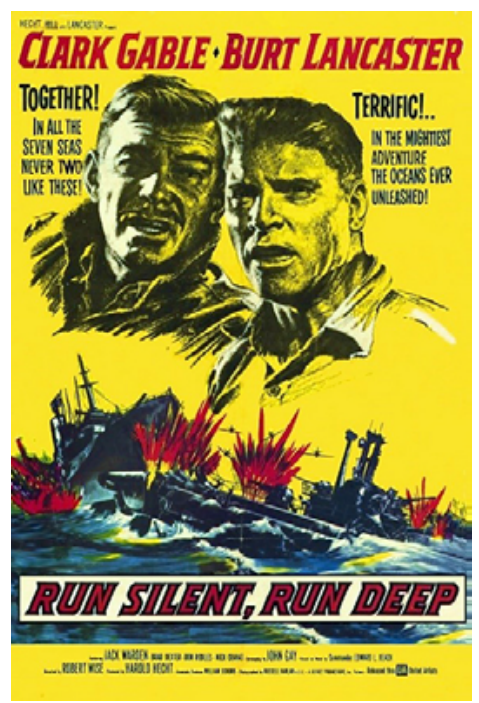

Fig. 1. Cartel promocional de Run Silent, Run Deep (Robert Wise, 1958).

Hecht-Hill-Lancaster Productions.

\section{SINOPSIS ARGUMENTAL}

\subsection{RUN SILENT RUN DEEP}

Run Silent Run Deep sitúa su historia en 1942 durante la Guerra del Pacífico y comienza con el hundimiento de un submarino de la Marina de los Estados Unidos perpetrado por un destructor japonés Akikaze en el canal de Bungo, cerca de la costa de Japón ${ }^{6}$. Su comandante, J.P. Richardson (Clark Gable), sobrevive al ataque y quedará marcado por la sed de venganza. Poco después, hastiado y reubicado en una oficina de la base norteamericana en Pearl Harbor, no dudará en solicitar el comando del USS $\mathrm{Nerka}^{7}$ al recibir noticias de su próxima patrulla cerca del canal. La denominada «zona 7» se ha cobrado nuevos hundimientos de la flota norteamericana y es temida entre la marinería. Secretamente, Richardson proyecta utilizar el submarino y su tripulación para introducirse unilateralmente en la zona y culminar su vendetta con el destructor de la Armada Imperial. Como consecuencia,

${ }^{6}$ La flota submarina norteamericana puso en servicio 288 submarinos durante la Segunda Guerra Mundial perdiendo 52, de los cuales 48 fueron hundidos en el Pacífico (Mata, cap. 1).

7 Se trata de una nave ficticia ya descrita en la novela. Para la filmación de sus tomas exteriores, la Marina cooperó prestando a la producción el USS Redfish, un submarino oceánico de Clase Balao (Rowan 2012: 136). 
el teniente Jim Bledsoe (Burt Lancaster), un joven primer oficial muy apreciado por la tripulación del Nerka, perderá su oportunidad de ascender en favor del desconocido Richardson, conservando el puesto de segundo a su pesar.

Tras un tenso encuentro en tierra y una vez asignado el mando, ambos deberán patrullar en un ambiente de incertidumbre: ni Bledsoe ni la tripulación confían en su nuevo comandante. Durante el trayecto, Richardson ordena duros ejercicios de entrenamiento y el submarino entra en combate exitosamente. No obstante, las incipientes sospechas sobre el destino secreto del Nerka darán pie a un conato de motín y graves problemas de convivencia.

Finalmente, el Nerka consigue llegar hasta los límites del canal de Bungo y se encuentra con un convoy japonés. Richardson decide atacar y consigue enviar a pique un barco de carga. El contraataque japonés por aire no tarda en llegar y es muy severo: el comandante resulta gravemente herido al golpearse, quedando incapacitado. Bledsoe asume el gobierno del Nerka y ambos se identifican en su determinación para regresar a la "zona 7», aliándose por primera vez desde el comienzo de la película.

La batalla final revela que el verdadero enemigo era un submarino japonés. El Nerka logra abatir al navío y al Akikaze enemigos en un ejercicio de total cooperación en el comando y alcanza la victoria. Richardson colapsa poco después de ver su objetivo consumado y muere. Bledsoe, ya como comandante, pondrá rumbo a la base en Pearl Harbor luego de oficiar un funeral militar en la mar, en el que declara: «que nadie aquí, nadie a bordo de esta embarcación pueda decir que no tuvimos un capitán».

\subsection{CRIMSON TIDE}

Crimson Tide es contemporánea de un hipotético año 1995, y da comienzo con un prefacio en pantalla: «Los tres hombres más poderosos del mundo: el presidente de los Estados Unidos, el presidente de la República Rusa... y el comandante de un submarino de misiles nucleares de los Estados Unidos»" ${ }^{9}$. A continuación, un noticiario informa sobre una grave crisis en la república: los rusos han bombardeado

${ }^{8}$ Existe un corte extendido de la película con 7 minutos extra que fueron eliminados en el montaje para las salas de cine. Este corte inédito se comercializó en formato DVD en 2006, pero la posterior reedición en disco Blu-ray de 2008 los volvería a eliminar. La mayor parte del nuevo metraje no contiene cambios sustanciales en la trama, ya que se trata de secuencias extendidas de camaradería entre la tripulación. Sin embargo, hay una escena que describe la buena relación personal entre Hunter y el contramaestre "COB" antes de la quiebra en el gobierno del Alabama. Estos minutos de metraje adicional aportan complejidad a la relación de «COB» con el comando y añade carga emotiva a su dilema.

9 Se perpetúa así el mito del submarino propuesto por Koldau bajo la definición de Howells: «un sofisticado concepto social de representación». En este caso en su versión excelsa: el temible submarino de misiles balísticos nucleares, un arma estratégica capaz de desatar el holocausto nuclear (Koldau 2011: 66). 


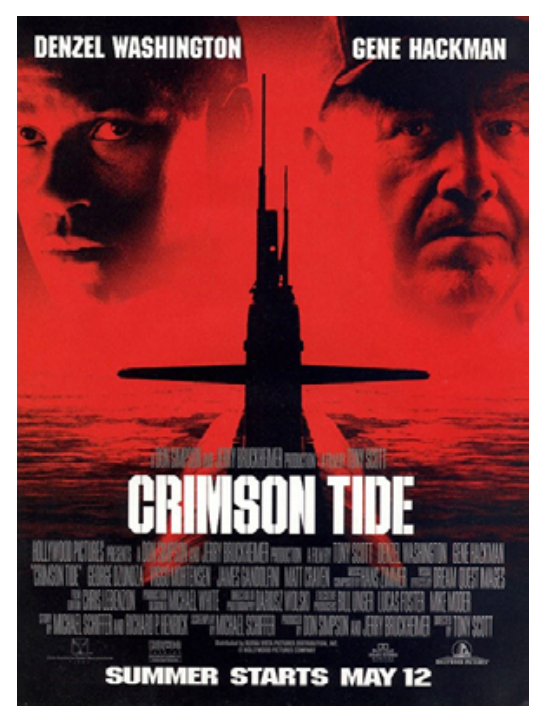

Fig. 2. Cartel promocional de Crimson Tide (Tony Scott, 1995). Hollywood Pictures y Don Simpson / Jerry Bruckheimer Films.

grupos rebeldes chechenos, lo que promueve sanciones internacionales como la suspensión de toda ayuda externa por parte de Estados Unidos. En consecuencia, el líder opositor ultranacionalista Vladimir Radchenko ${ }^{10}$ (Daniel von Bargen) provoca un enfrentamiento al borde de la guerra civil en el país y toma el control de una base nuclear de misiles intercontinentales bajo la amenaza de ataque a los Estados Unidos en caso de intromisión.

La crisis internacional moviliza a la Armada para poner en servicio al USS Alabama (SSBN-731), un submarino nuclear de Clase Ohio que existe como tal en la realidad y que forma parte de la flota de la Marina de los Estados Unidos desde su botadura en 1984 (Submarine Force Pacific 2020). El veterano capitán Frank Ramsey (Gene Hackman) comanda una misión hacia latitudes de ataque, para la que alista al joven teniente Ron Hunter (Denzel Washington) como primer oficial. Desde el comienzo de su cogobierno quedará patente que se trata de dos hombres de diferente filosofía: mientras Ramsey es un marino de la vieja escuela y cree en el cumplimiento de la orden y el buen oficio Hunter tiene una educación moderna de corte intelectual, con una visión y valores complejos.

El cisma en el comando surgirá con la orden de atacar con armamento nuclear en suelo ruso, para lo que comandante y primer oficial acuerdan comenzar el proce-

${ }_{10}$ El personaje puede haber sido concebido como una exageración del efímero presidente interino Aleksandr Rutskói. 
dimiento de disparo. Poco después, durante un enfrentamiento submarino, la nave recibe otro mensaje referente al uso de los misiles, pero llega incompleto debido a la profundidad. Ramsey entonces decide proceder unilateralmente con el lanzamiento sin el consentimiento de Hunter. El primer oficial tiene serias dudas sobre el contenido del segundo mensaje: podría tratarse de una contraorden para cancelar el disparo $^{11}$. Sin conseguir llegar a un consenso, Hunter ordena reemplazar a Ramsey y toma el gobierno. El nuevo líder del Alabama deberá mediar con la tripulación, muy dividida, y solventar el problema de recepción del segundo mensaje. Poco después, el bando afín a Ramsey retoma el control del submarino por la fuerza en el mismo momento en el que, finalmente, el Alabama recibe el segundo mensaje íntegro. La orden es abortar todo ataque. Ramsey, derrotado, cede el comando a Hunter.

De regreso a la base en Pearl Harbor, ambos serán requeridos por una junta de investigación en el Cuartel General de la Flota del Pacífico, donde el contraalmirante Anderson (Jason Robards) resuelve lo siguiente: «pudo tener la razón Hunter, pero en lo tocante a la ley ambos la tenían y ambos estaban equivocados». Al disolverse la junta, los dos comandantes tendrán un breve encuentro de reconciliación. El epílogo de la película anuncia una actualización del decreto por el cual la decisión de lanzar misiles nucleares es autorizada únicamente por presidente de Estados Unidos como comandante en jefe.

\section{CRISIS DEL COMANDO EN EL CINE DE GUERRA SUBMARINA NORTEAMERICANO}

La película bélica naval Caine Mutiny (Edward Dmytryk, 1954) comienza con la siguiente leyenda en pantalla: «Nunca ha habido un motín en un barco de la Marina de los Estados Unidos». No obstante, en el historial del servicio de Marina de superficie norteamericana se pueden hallar referencias documentales de amotinamientos o sucesos de reemplazo del comando en tiempos de guerra ${ }^{12}$. En lo que concierne a las naves de oficio submarino, resulta muy complicado localizar un incidente de la misma naturaleza; hasta el recientemente difundido caso del USS Florida, que tuvo como conclusión el relevo de su comandante en el año 2018 ( $\mathrm{La}$ Razón 2019) $)^{13}$.

${ }^{11}$ Este episodio tiene su equivalencia histórica en el incidente ocurrido durante la crisis de los misiles de Cuba en 1962 a bordo del submarino soviético B-59. La nave fue sitiada por buques de superficie norteamericanos que soltaron cargas de profundidad inocuas a modo de señal para que el submarino emergiese. Creyéndose bajo ataque, el capitán del B-59 estuvo a punto de ordenar el disparo de armamento nuclear desde las profundidades, donde no hay contacto posible por radio. El voto en contra del comandante Vasily Arkhipov para autorizar el uso de la fuerza evitó el desastre (Ketov 2005: 217-231).

${ }^{12}$ Más de un siglo antes del estreno de la película de Dmytryk, sucedió el motín del USS Somers durante la intervención estadounidense en México en el año 1842.

${ }_{13}$ Un incidente de índole sexista se desencadenó por la redacción de unas «listas de violación» por parte de algunos marineros. Como resultado se tomó la decisión de destituir al coman- 
Durante la Segunda Guerra Mundial, eran habituales los filmes producidos en Hollywood con destacados elementos de propaganda, como Destination Tokyo (Delmer Daves, 1943), una heroica aventura de guerra submarina donde nunca se cuestiona al comando. De hecho, el capitán del USS Copperfin, encarnado por el carismático Cary Grant, es retratado en la película como la idealización de un padre bondadoso. No obstante, ya en la posguerra, el cine bélico norteamericano comienza a abandonar las historias de personajes unidimensionales para avanzar hacia relatos basados en los conflictos del gobierno y el cuestionamiento de la figura patriarcal. Los estudios de Hollywood proyectaban este escenario argumental como espacio de duelo interpretativo para sus estrellas, recurriendo a las historias de ficción, sumando la atractiva estética bélica y el suspense al servicio del drama (Koldau 2012: 114). Bajo esta temática y enmarcadas en el servicio de marina de superficie, debuta la ya mencionada Caine Mutiny y también Away All Boats! (Joseph Pevney, 1956). En lo que respecta a las películas en dotaciones submarinas, se estrena la aquí analizada Run Silent Run Deep, y también Torpedo Run (Joseph Pevney, 1958), Submarine Seahawk (Spencer Gordon Bennet, 1958) o Up Periscope (Gordon Douglas, 1959). Estos filmes sitúan en el centro del drama el conflicto personal y/o profesional en base a una contraposición de objetivos entre los personajes del hábitat submarino y están especialmente representados en la figura del comandante y el primer oficial. Las estrategias narrativas aplicadas al relato no están exentas de matices edípicos y siempre derivan en un grave perjuicio en las relaciones del comando con el resto de la marinería. Por lo tanto, la batalla contra el enemigo externo, determinante en los relatos bélicos rodados en tiempo de guerra, ocupa en estas películas una función contextual y asume el rol de generador de tensión para un argumento basado principalmente en la quiebra de la convivencia.

Rayner describe las singularidades que el cine de guerra submarina presenta respecto a la crisis del comando en relación con otros subgéneros bélicos. También resulta especialmente reveladora su observación sobre la habitual restauración y refuerzo de la imagen de la autoridad y, por lo tanto, de la Marina, en las conclusiones de estas películas junto con las enmarcadas en la guerra naval de superficie:

... The insubordination appears more serious, and comes closer to outright mutiny, in the submarine films may be related to their representational specificity. [...] The confinement of the submarine's internal spaces, allied to the boat's remoteness from the chain of command, may make the narrative and military authority of the commander appear more arbitrary, and as a result more likely to provoke confrontation. [...] As in the films which treat surface ships, the Oedipal threat is never fully realised, and the subordinate officers accept their institutional roles, or achieve command authority themselves, if only when the patriarch bequeaths

dante. La ausencia de mujeres en la tripulación de los submarinos militares norteamericanos fue una realidad hasta hace pocos años. Este hecho ha convertido al subgénero en "películas masculinas», hasta el punto que la intromisión de la mujer a bordo ha dado pie para la realización de comedias, como el caso de Operation Petticoat (Blake Edwards, 1959). 
it. [...] The implied rebellion is not only contained, but ultimately reversed, to produce a picture of appropriately distributed, exercised and inherited authority, which reinforces rather than challenges the patriarchal naval establishment (Rayner 2007: 109-114).

\section{RUN SILENT RUN DEEP Y CRIMSON TIDE: DOS VARIANTES DE LA CRISIS DEL COMANDO EN EL CINE DE GUERRA SUBMARINA}

\subsection{LA CARACTERIZACIÓN DE LOS PERSONAJES PROTAGONISTAS}

La lucha de perfiles opuestos es el eje central de las dos películas estudiadas. El comandante y el primer oficial ocupan puestos de poder, respeto y liderazgo en los submarinos. Sin embargo, estos personajes confrontan entre sí al mismo tiempo que trabajan en equipo, lo que amplifica enormemente las posibilidades dramáticas. Ambos se pueden definir fundamentalmente en un binomio estereotipo entre un hombre joven y capacitado en contraposición a la figura del hombre maduro y experimentado encarnado por el comandante. Pese a ello, la contradicción que expresan los retratos de Richardson y Ramsey, ambos obstinados y, en última instancia, aciagos, aporta dimensión a los caracteres; lo que los convierte en protagonistas vehiculares para el modelo de relato (McKee 2002: 446-460).

El comandante Richardson se presenta en Run Silent Run Deep como un hombre de familia de edad avanzada ${ }^{14}$, marino curtido, derrotado en el campo de batalla y con una gran determinación por materializar su deseo de venganza. La opinión que pueda tener la tripulación de su persona y su modo de gobernar le es indiferente ${ }^{15}$. De hecho, puede llegar a ser intransigente en los ejercicios de ataque y simulacros con la marinería, que es, a su modo de ver, una mera herramienta para alcanzar sus objetivos. De la misma manera, llegará a desacatar órdenes de la Marina para reubicar la posición del navío a riesgo de abandonar su guerra particular. En el desempeño del comando resulta brillante en las tácticas de ataque; pero tras diferentes encuentros enemigos, la tripulación del Nerka no advierte a identificarlo como cobarde o temerario. No obstante, Richardson no es retratado como el villano de Run Silent Run Deep. Se trata de un personaje definido por la obsesión y fracturado por la derrota. En aras de un patriótico sentido de la lucha contra el enemigo, el comandante conseguirá alinearse con su primer oficial en el tramo final de

${ }^{14}$ Clark Gable se encontraba en un delicado estado de salud durante el rodaje de la película. Puede observarse al actor sufriendo temblores en muchas de las escenas, un detalle que aporta un viso trágico al personaje. El actor murió el 16 de noviembre de 1960, dos años después del estreno de la película.

15 De la misma manera que en Crimson Tide, la dureza del comandante en el trato con la tripulación se contrapone a la empatía dispensada por parte del primer oficial. 


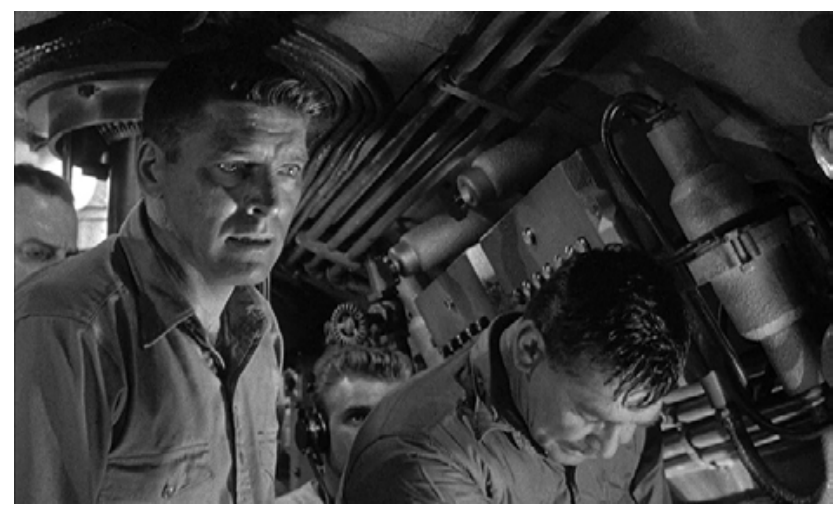

Fig. 3. Richardson cede el liderazgo a Bledsoe durante el último acto de Run Silent Run Deep (Robert Wise, 1958). Hecht-Hill-Lancaster Productions.

la película. Richardson llegará a consumar su objetivo y destruir al enemigo, pero también será víctima de sus acciones, lo que le convierte en un personaje trágico ${ }^{16}$.

Por el contrario, el teniente Jim Bledsoe es un hombre joven, íntegro y que cree en el cumplimiento de las normas de la Marina. Burt Lancaster aporta su carisma al personaje, pero el actor modera su reconocida sonrisa para ofrecer una composición más dramática de la habitual. Bledsoe tiene capacidad para imponer el liderazgo y también es de carácter empático: muestra un sincero respeto por la familia de tripulantes que habita el Nerka y estos, a su vez, le corresponden. No obstante, deberá lidiar con la contradicción de estar al servicio en patrulla para un comandante que ha interceptado su ascenso. Bledsoe tiene la difícil tarea de coordinar gobierno y una recelosa tripulación, al mismo tiempo que examina su audacia para dirigir maniobras de ataque con riesgo mortal; la lección definitiva para postularse como líder del submarino ${ }^{17}$.

Comandante y primer oficial alternan el punto de vista de la puesta en escena en la películas de Wise, lo que repercute en mejorar la calidad del retrato para ambos e intensifica la empatía con la audiencia. Es el caso contrario a lo observado en Crimson Tide, donde rara vez se adopta la perspectiva del comandante en contraposición al protagonismo de Hunter.

${ }^{16}$ La obsesión del personaje liga directamente al autodestructivo capitán Ahab y su empeño por dar caza a la «ballena blanca» en Moby Dick (Herman Melville, 1851).

17 Resulta característico en el arco evolutivo del primer oficial el relato de aprendizaje para postularse a comandante. Al igual que en el caso de Hunter en Crimson Tide, esta instrucción tiene como objetivo sobrevivir a una guerra dentro del "hogar submarino» y también a la que se libra en el mundo exterior. 


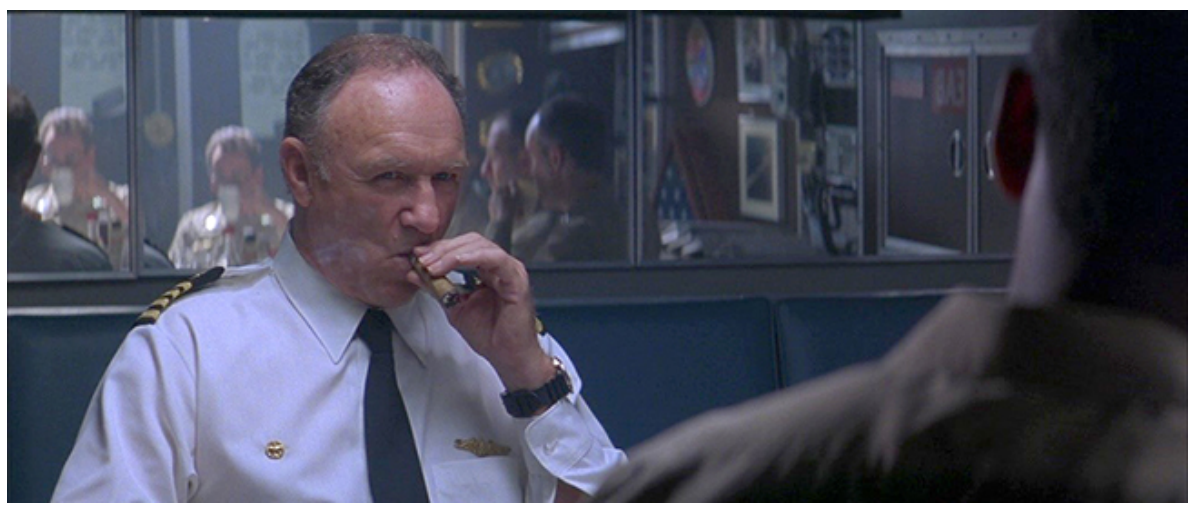

Fig. 4. El comandante Ramsey fuma un puro (símbolo del comando) en Crimson Tide (Tony Scott, 1995). Hollywood Pictures y Don Simpson / Jerry Bruckheimer Films.

El capitán Frank Ramsey es encarnado por Gene Hackman en Crimson Tide. $\mathrm{El}$ actor proporciona al personaje su estilo contundente y resulta de una personalidad implacable en pantalla. Ramsey es el retrato de un hombre experimentado en combate y con reputación de ser muy exigente en el servicio. Del ámbito privado se sabe que tiene familia, pero está divorciado (se pueden observar en varias escenas de la película abundantes fotos de familia en su camarote, momentos de una vida tal vez ya pasada). Su desestructurada historia personal se insinúa estar ligada al gran compromiso que siente por la Marina. La lealtad a su mascota Bear, un jack russel terrier, lo avala a su vez como un hombre sensible ${ }^{18}$. Todo su apego exclusivo por la vida profesional parece ser generador de intransigencia cuando se trata del compromiso de la seguridad nacional, llegando al extremo de ser brutal en el momento de ejercer su autoridad. Ideológicamente, se trata de un personaje caracterizado por su fe en las certezas y el acatamiento del orden militar. El comandante Ramsey nunca aceptará el hecho de haber errado en su empeño por disparar las armas nucleares en Crimson Tide. Sin embargo, su obstinación no se sitúa en el terreno de un belicismo exacerbado tanto como en la convicción del ataque preventivo como medida proteccionista y el acatamiento del deber sin ambigüedades.

El teniente Ron Hunter es un joven primer oficial que representa la nueva escuela militar, con un historial de educación superior, pero sin experiencia en combate real. Denzel Washington interpreta a Hunter con la energía y determinación que caracteriza al personaje. El teniente es un hombre de familia afroamericano ${ }^{19}$

18 Un matiz en la caracterización del personaje que aporta volumen al retrato y contrasta con su marcado autoritarismo.

19 La película fue concebida poco después de los graves disturbios raciales de Los Ángeles en 1992. En Crimson Tide, el teniente Hunter llegará a ser sometido a abuso físico en una situación 


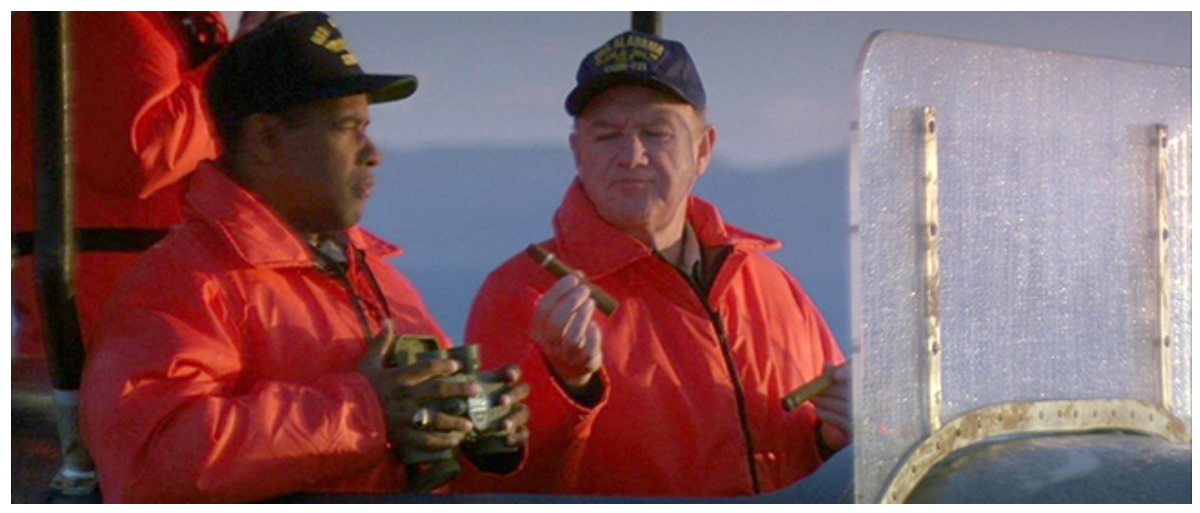

Fig. 5. Hunter es obsequiado con el "puro del comando" por parte de Ramsey. Crimson Tide (Tony Scott, 1995). Hollywood Pictures y Don Simpson / Jerry Bruckheimer Films.

felizmente casado: desde las primeras secuencias de la película, el espectador tiene acceso a la privacidad de su hogar, donde sigue con preocupación la última hora del conflicto internacional ${ }^{20}$. El riesgo real de guerra nuclear acentuado posteriormente por las unilaterales decisiones de Ramsey pondrá en peligro el contexto familiar que Crimson Tide describe en la residencia de los Hunter. Durante su patrulla en el Alabama, el primer oficial se caracteriza por la buena aplicación del reglamento, por sus ideas en clave positiva y por la conveniencia de la tripulación. Hunter encarna al héroe protagonista en el relato de Crimson Tide, y el espectador lo percibe así por empatía hacia la posible y devastadora pérdida personal a la que se enfrenta.

El origen de la relación entre comandante y primer oficial presenta de forma preliminar posicionamientos antagónicos de ambas partes, trazando el arco narrativo por el cual su relación se desarrollará. En algunos casos, estas escenas se extienden como instrumento de presentación de alguno de los dos caracteres ${ }^{21}$. Run Silent Run Deep propone un inesperado tono formal-informal, inclusive de farsa para la primera escena compartida por los personajes protagonistas. El momento comienza con la llegada de Bledsoe a la residencia de los Richardson vistiendo uniforme (símbolo

de vulnerabilidad. La escena en cuestión describe al primer oficial resignado a la brutalidad de un autoritario Ramsey en la sala de control, que lo golpea en varias ocasiones. La analogía entre este clímax de la crisis doméstica del Alabama y las revueltas en consecuencia del linchamiento a Rodney King por parte de un grupo de policías del LAPD señala a una posible investigación al respecto.

${ }_{20}$ Al contrario que el caso de Bledsoe en Run Silent Run Deep, sí podemos conocer la vida personal de Hunter. La ausencia de referencias sobre la vida privada de Bledsoe en tierra acentúa su papel como aspirante a "padre» del hogar alternativo, el Nerka, y la relación fraternal con la marinería.

${ }^{21}$ Ese es el caso de Crimson Tide, donde la escena de la entrevista también muestra al personaje del comandante Ramsey por primera vez en la pantalla. 


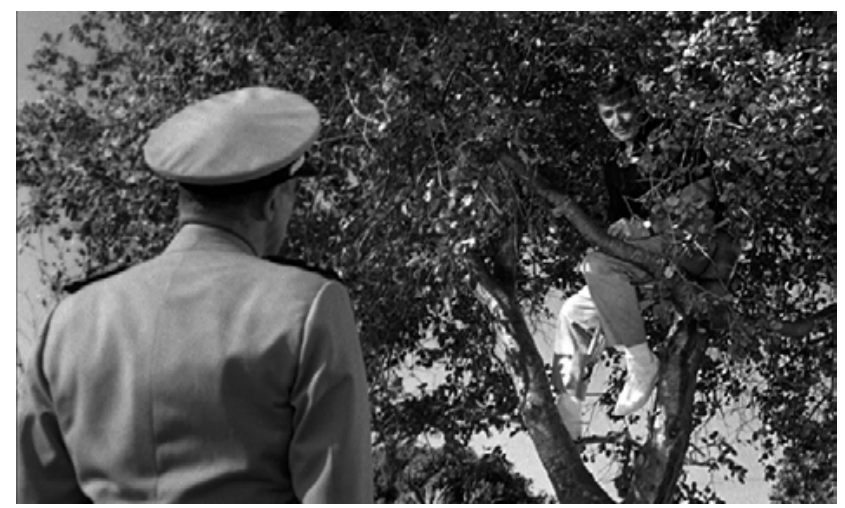

Fig. 6. Bledsoe se encuentra por primera vez con Richardson en su residencia. Run Silent Run Deep (Robert Wise, 1958). Hecht-Hill-Lancaster Productions.

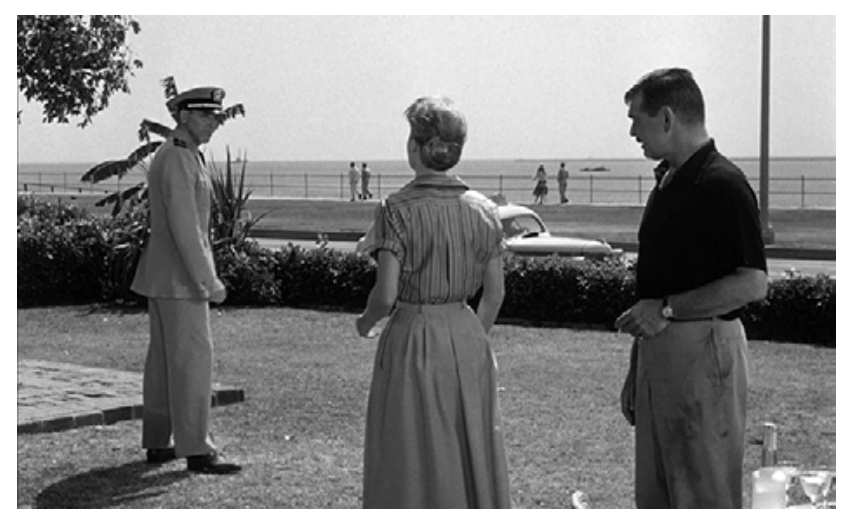

Fig. 7. Bledsoe y los Richardson durante la promesa. Tras ellos, el mar es testigo. Run Silent Run Deep (Robert Wise, 1958). Hecht-Hill-Lancaster Productions.

del oficio y la integridad). El primer oficial acude predispuesto al enfrentamiento y se encontrará con su comandante encaramado a un árbol del jardín con ropa de civil. Se inicia así, en un falso tono de comedia de equívocos, el duelo dentro del comando, proponiendo un equilibrio en la percepción por parte del espectador de ambos personajes protagonistas al situar al severo Richardson en el terreno de lo ordinario. En la escena también interviene Laura Richardson (Mary LaRoche), que fuerza las posiciones del uno y del otro en un triángulo hacia la buena colaboración. Laura comprometerá bajo una promesa a Bledsoe para velar por la vida de su marido, que viste durante la escena una premonitoria camisa negra.

Crimson Tide plantea la escena del primer contacto durante una noche de tormenta en el interior de las dependencias del comandante Ramsey. De nuevo se 

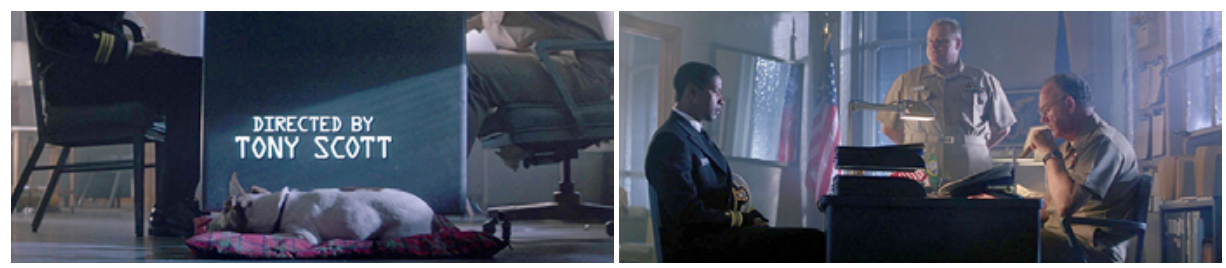

Fig. 8. El perro Bear avala a Hunter como primer oficial del Alabama en Crimson Tide (Tony Scott, 1995). Hollywood Pictures y Don Simpson / Jerry Bruckheimer Films.

establece una relación a tres partes, a la que se sumaría Bear, el terrier ${ }^{22}$. El contramaestre "COB»" ${ }^{23}$, ubicado simbólicamente entre Hunter y Ramsey, ejerce de testigo en una suerte de "entrevista-enlace»" ${ }^{24}$ Al contrario que el caso de Run Silent Run Deep, la escena se plantea manteniendo un formato militar y no implica una predisposición a la confrontación. Sin embargo, el comandante deja patente durante la conversación que debe sustituir a su estimado primer oficial por una baja, algo que visiblemente parece no resultarle cómodo a pesar de las buenas referencias del desconocido Hunter: «su nombre encabeza la lista. [...] era una lista muy corta». Durante la lectura del historial de Hunter, Ramsey muestra su sorpresa al leer el período de formación en la Universidad de Harvard. El comandante no parece que apruebe la educación superior como mérito en la Marina. Acto seguido, pregunta sobre intereses personales a Hunter, que responde sobre su afición por la equitación. Esta conversación será retomada en posteriores momentos clave de la película y representa en forma de diálogo una reconfiguración de la relación entre ambos hacia un trato entre dos partes iguales, entre "dos hombres».

El terrier del comandante tiene una inesperada importancia en el desarrollo de la escena, ya que dará la bendición final al mostrar su empatía con Hunter, cosa que Ramsey reconoce: "parece que usted le gusta». La importancia de Bear en la escena liga con el tono formal-informal visto en Run Silent Run Deep para su versión de la entrevista entre el comando. Tony Scott prolonga la farsa al situar su crédito como director en la escena de forma juguetona sobre la figura del terrier, ajustado en el espacio que distancia a los dos protagonistas.

${ }^{22}$ El comandante declara sobre su apreciada mascota: «no hay perro más inteligente que los jack russel, va a todos lados conmigo". Aquí la fidelidad de Bear con su amo parece servirse como ejemplo del comandante para con su primer oficial: la lealtad y el acatamiento como modelo de conveniencia para las buenas relaciones entre líder y subordinado.

${ }^{23}$ En Crimson Tide la marinería del Alabama es nombrada por las siglas de su cargo. Para el caso del contramaestre Walters resultaría "COB», de "Chief of the Boat» en inglés.

${ }^{24}$ Durante la escena puede escucharse la sonata n. ${ }^{\circ} 14$ para piano o "Claro de luna» de Beethoven. La pieza fue dedicada a la joven condesa Guicciardi, alumna del músico. Es conocido que el autor y la condesa vivieron una relación de amor utópica debido a la posición social incompatible entre ambos. La sonata expresa este sentimiento de melancolía y Crimson Tide se sirve de ella para transmitir el comienzo de un enlace sin futuro entre el comando. 
Otra escena de Crimson Tide localizada en el comedor de los oficiales durante el primer acto de la película expone claves ideológicas de los dos personajes. En ambiente de sobremesa, el comandante Ramsey charla coloquialmente sobre el manejo del armamento nuclear con su primero de a bordo: "[...] la Marina me quiere simple», «yo solo tengo que saber cómo apretar un botón y ellos [el comando en base] me dicen cuándo», y añade citando a Karl von Clausewitz: «la guerra es política continuada por otros medios $\aleph^{25}$. Hunter lo secunda, pero también aclara: «[...] la guerra tiende a servirse a sí misma» $\mathrm{y}$ «en el mundo nuclear el verdadero enemigo es la guerra». La opinión del primer oficial sobre el desempeño nuclear podría ser interpretada como pacifista, pero reside en el temor a la realidad que puede desencadenar el ataque y contraataque nuclear: un holocausto. Por parte de Ramsey, resulta inverosímil que el capitán de un submarino estratégico nuclear tenga una mentalidad propia de ataque convencional cuando se trata de desempeñar armas de esa naturaleza. Aun tratándose de un ataque preventivo a sabiendas de que el enemigo se está armando, es probable que la presencia de Hunter en la sala de control acentúe la terquedad de Ramsey y se justifique así por motivos de contraste ideológico, lo que coincide con la afirmación de Koldau sobre el incremento de la tensión psicológica en el cine de guerra submarina nuclear (Koldau 2012: 113).

\subsection{LA COMPLEJA RECIPROCIDAD DEL COMANDO CON LA TRIPULACIÓN: SUBLEVA- CIÓN Y DEFENSA}

El vínculo del comandante y del primer oficial con el equipo humano del navío es muy importante en la relación de fuerzas que se verán confrontadas. La tripulación tiene en última instancia el papel de reconocer o rechazar la autoridad de sus superiores. El cuadro de alianzas enfrentadas que se generan tras la quiebra del gobierno define de gran manera el devenir del conflicto. Si bien las competencias del segundo de a bordo están especialmente ligadas a un trato directo con la tripulación, el comandante también permanece en contacto con la marinería debido a las características espaciales y de proximidad propias de los navíos submarinos, y ambos se encuentran en la compleja posición de aunar gobierno, disciplina y moral.

En el primer acto de Run Silent Run Deep, el comandante Richardson, hastiado en la base en Pearl Harbor, mantiene estrecha complicidad con el subalterno Mueller, un hombre que conoce su secreta obsesión por cazar el destructor Akikaze, y que además le alienta a lograr su objetivo. Ambos compartirán destino en la patrulla del Nerka, lugar en el que Richardson cuenta únicamente con la amistad de su confidente. Mueller defenderá el honor del capitán durante toda la travesía, llegando a agredir al oficial Cartwright (Brad Dexter) tras una burla sobre su estado de salud. El comandante no tendrá más aliados durante la patrulla, y todos

25 Cita tomada del tratado De la Guerra (Karl von Clausewitz, 1832). Clausewitz fue un militar y teórico de la ciencia militar de gran influencia cuya obra es estudiada en las academias militares. 


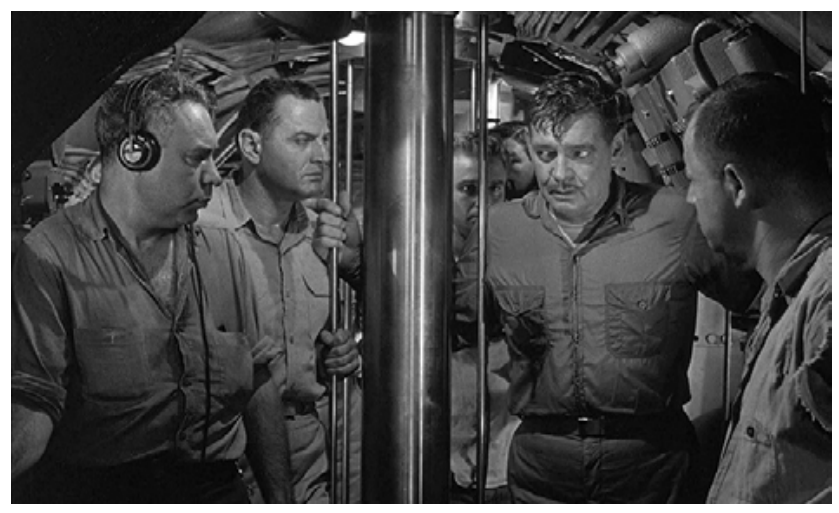

Fig. 9. Richardson es increpado en silencio por su tripulación en Run Silent Run Deep (Robert Wise, 1958). Hecht-Hill-Lancaster Productions.

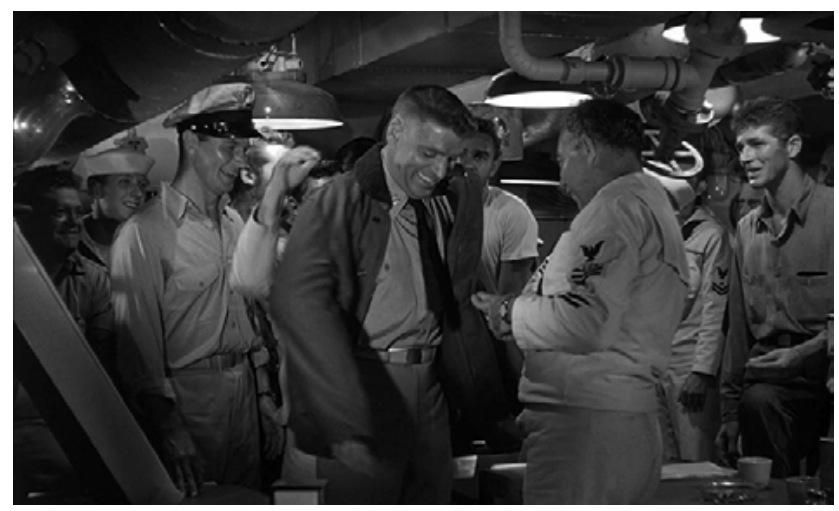

Fig. 10. Bledsoe recibe una chaqueta de capitán como obsequio de la tripulación del Nerka. Run Silent Run Deep (Robert Wise, 1958). Hecht-Hill-Lancaster Productions.

los oficiales manifiestan unánimemente el rechazo a Richardson cuando acuerdan planificar en secreto su reemplazo.

El primer oficial Bledsoe se presenta en pantalla durante una escena donde la tripulación del Nerka le hace entrega de una chaqueta ad hoc de comandante en un ambiente festivo. La cazadora actúa como un símbolo de la consolidación como miembro distinguido en el hogar submarino en el que conviven, así como el visto bueno para su ascenso. Poco después, la decepción del primer oficial al verse socavado del comando será igualmente compartida por sus compañeros.

Una vez desatada la crisis en el Nerka, la misma tripulación, representada en sus oficiales, apela al pacto de concordia con su primer oficial y lo convoca en secreto para proponer la destitución del comandante. Nada de ello bastará para evitar que Bledsoe disuelva la asamblea sin paliativos y elimine así toda opción de amotina- 


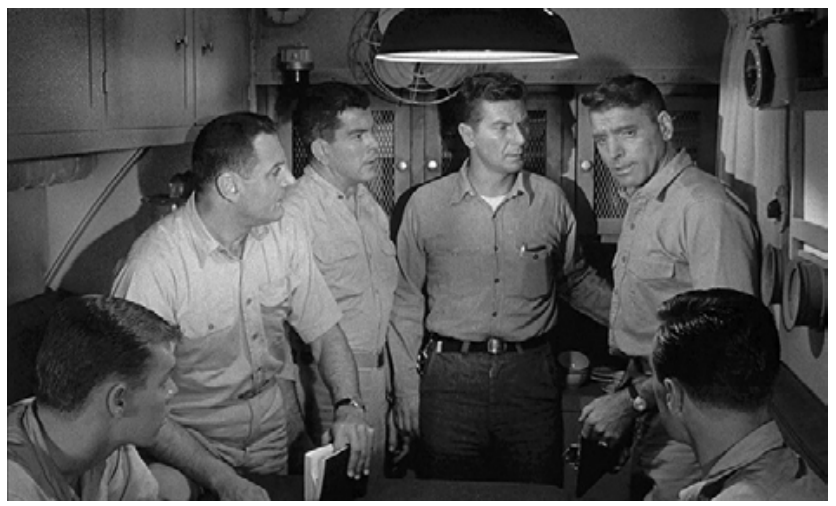

Fig. 11. Bledsoe es propuesto en secreto por la tripulación para sustituir al comandante. Run Silent Run Deep (Robert Wise, 1958). Hecht-Hill-Lancaster Productions.

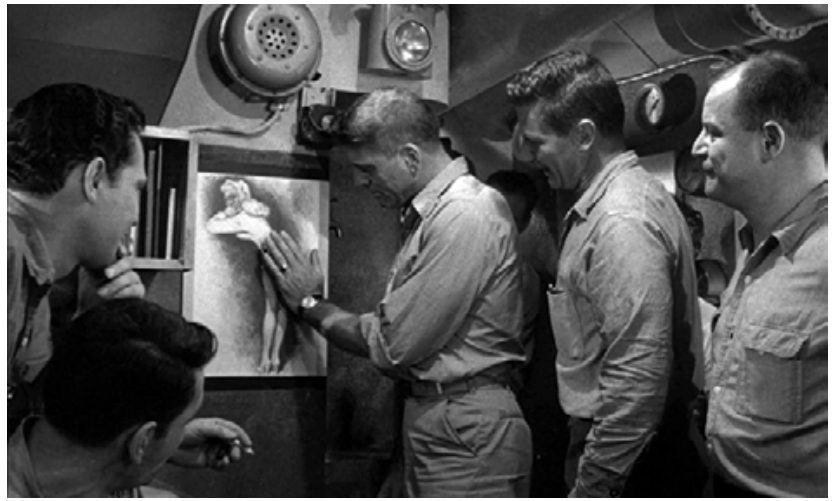

Fig. 12. El primer oficial es cordialmente invitado a participar en el ritual de la buena suerte. Run Silent Run Deep (Robert Wise, 1958). Hecht-Hill-Lancaster Productions.

miento, a pesar de la abrumadora unanimidad contra el gobierno de Richardson, inclusive la suya propia ${ }^{26}$. Todo ello pone en una situación delicada al primer oficial, ya que pierde temporalmente la confianza de sus oficiales.

Hacia el final de la película, la consolidación de Bledsoe como comandante de facto en el Nerka se sellará mediante otro acto simbólico instigado por el contramaestre Kohler (Joe Maross) y la tripulación: participar en una rutina entre los hombres de palmar el dibujo de la única tripulante femenina del submarino en forma de dibujo en la pared.

${ }^{26}$ Este hecho proclama la integridad de Bledsoe respecto al cumplimiento estricto de las normas, una característica habitual en el personaje del primer oficial. 


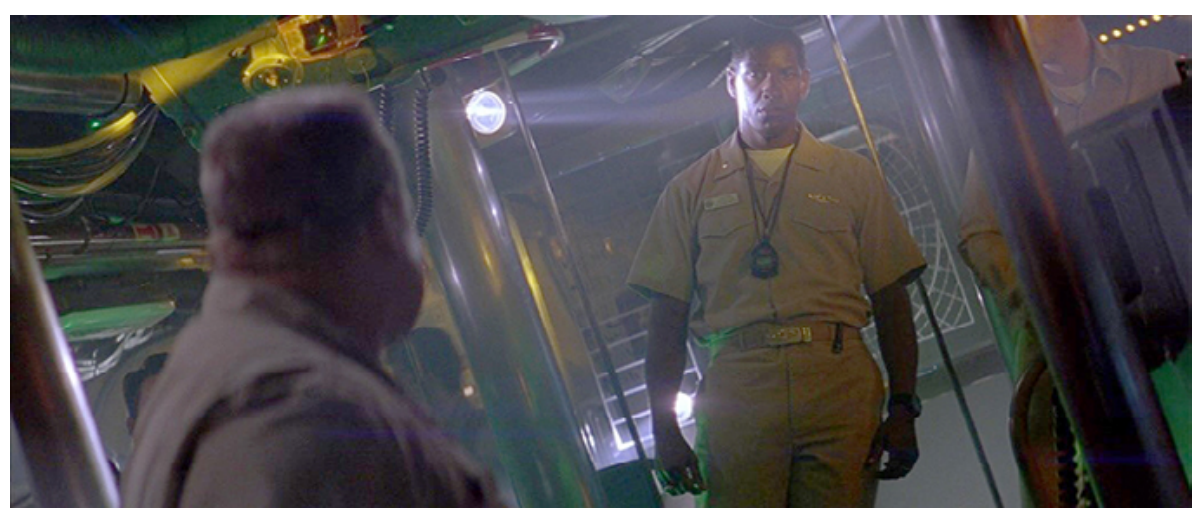

Fig. 13. «COB» apremia a Hunter para tomar una decisión de dramáticas consecuencias. Crimson Tide (Tony Scott, 1995). Hollywood Pictures y Don Simpson / Jerry Bruckheimer Films.

Por su parte, en Crimson Tide, el comandante Ramsey parece mantener una estrecha relación profesional con el contramaestre Walters «COB». Ambos se presentan en pantalla de forma simultánea y se da por supuesta una trayectoria conjunta en el Alabama ${ }^{27}$. No hay demostración de afinidad del comandante hacia el resto de su tripulación más allá del discurso que les dedica al comienzo de la patrulla. De hecho, este rechaza el trato empático propuesto por Hunter al avisar de la creciente tensión entre la tripulación de la nave una vez iniciada la misión.

Tras el incidente que provoca la revocación del comandante Ramsey, la tripulación del submarino queda en estado de shock al encontrarse sin un líder inequívoco. El primer oficial pasa a ser comandante accidental y no cuenta con la aprobación moral de la marinería. Hunter debe emplear el reglamento y la lógica para justificar su decisión de luchar por el control del $A_{l a b a m a^{28}}$, algo que le resulta complicado al no poder apelar a un vínculo personal más allá del oficial de armas Peter Ince «WEPS» (Viggo Mortensen). El nuevo e inexperimentado capitán conseguirá revertir la percepción de codicioso por una parte de la tripulación gracias a su buen oficio en el hundimiento del submarino Akula enemigo. Hunter también afrontará la difícil decisión de ordenar la muerte segura de tres hombres para salvar la nave durante unas maniobras de drenaje de emergencia; otra prueba extrema para alcanzar el estatus simbólico de comandante.

${ }^{27}$ No obstante, en la escena del corte extendido de la película mencionada anteriormente, Ramsey traslada a Hunter resolver con «COB» el «delicado tema de su sobrepeso». De este modo, Ramsey se exime de tener un encuentro incómodo con su contramaestre, lo que indica una relación tal vez no tan cercana. Por otro lado, debido a este asunto, Hunter estrechará lazos con el capataz.

${ }^{28}$ Inmediatamente después del relevo del capitán Ramsey, Hunter insta a que cualquier miembro de la sala de control abandone su puesto si está en desacuerdo con su decisión. De esta manera la actuación de Hunter se muestra como transparente a su tripulación. 


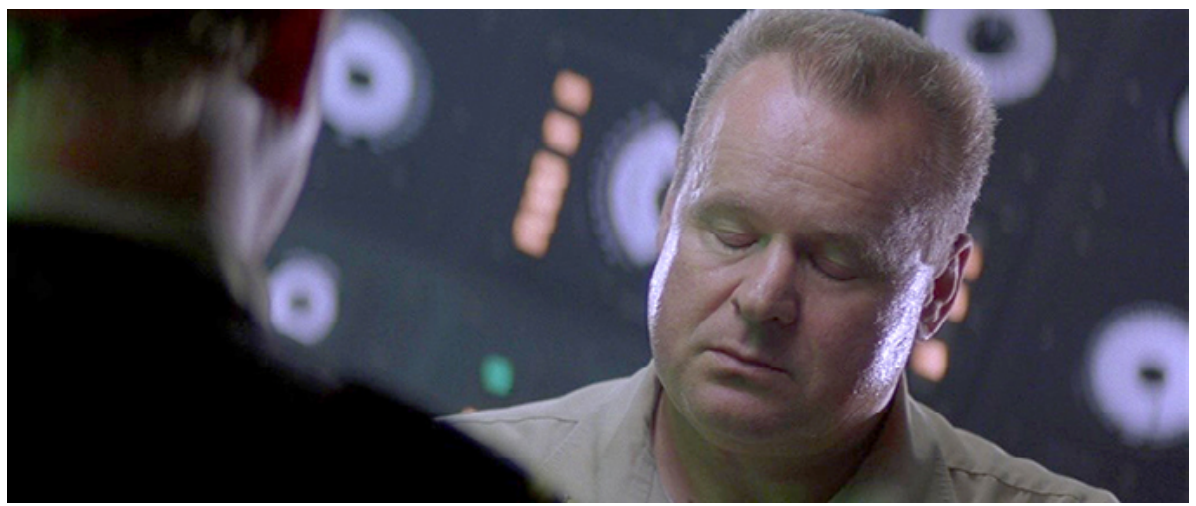

Fig. 14. El depuesto Ramsey reprende a "COB» tras retomar el gobierno del Alabama en Crimson Tide (Tony Scott, 1995). Hollywood Pictures y Don Simpson / Jerry Bruckheimer Films.

Varios de los oficiales en el Alabama lideran un motín para restituir al comandante en el último tercio de la película. La motivación de sus actos parece justificarse por el posicionamiento respecto al dilema del disparo del armamento nuclear, y no tanto por una vinculación personal con su comandante. Los oficiales Dougherty «SUPPO» (James Gandolfini), Zimmer «COMMO» (Matt Craven) y Westerguard "OPS-O» (Rocky Carroll) son los instigadores. Por su parte, el contramaestre "COB» cita el reglamento y no apoya Ramsey en su cruzada, dirigiendo el servicio de arresto al excomandante. Hunter agradece su apoyo en una conversación privada, pero solo encuentra la indiferencia del contramaestre: «entiéndalo bien, yo no estoy de su parte». Más tarde, Ramsey y «COB» tendrán un encaramiento tras su retorno al poder por asalto y, visiblemente defraudado, le recrimina su traición frente a la tripulación en la sala de control.

De entre el sector oponente a Hunter, se encuentra su amigo "WEPS». El teniente es uno de los invitados al cumpleaños en el hogar de los Hunter en el comienzo de la película y también el único miembro de la tripulación del Alabama que tiene acceso a su vida privada. También es quien presenta a Hunter a los nuevos oficiales del Alabama antes de comenzar la patrulla, puesto que el primer oficial desconoce prácticamente a toda la tripulación. No obstante, «WEPS», bajo presión, traicionará a su amigo para reponer el statu quo inicial, pero no quedará convencido de su propia actuación.

El abandono del círculo de confianza de Hunter por parte de «WEPS» arrincona al primer oficial, que se vuelve a dirigir a su facción durante la reclusión forzosa a la que se ven sometidos: «esto no es un motín, yo seguí las reglas». "COB», también aprisionado por fidelidad a Hunter, le manifiesta sus dudas: «la mitad de mí celebra el retorno del comandante, puede tener la razón». El personaje del contramaestre pivota entre las dos fuerzas en el Alabama constantemente, pero será guiado por el argumento de Hunter en el último tercio de la historia. 


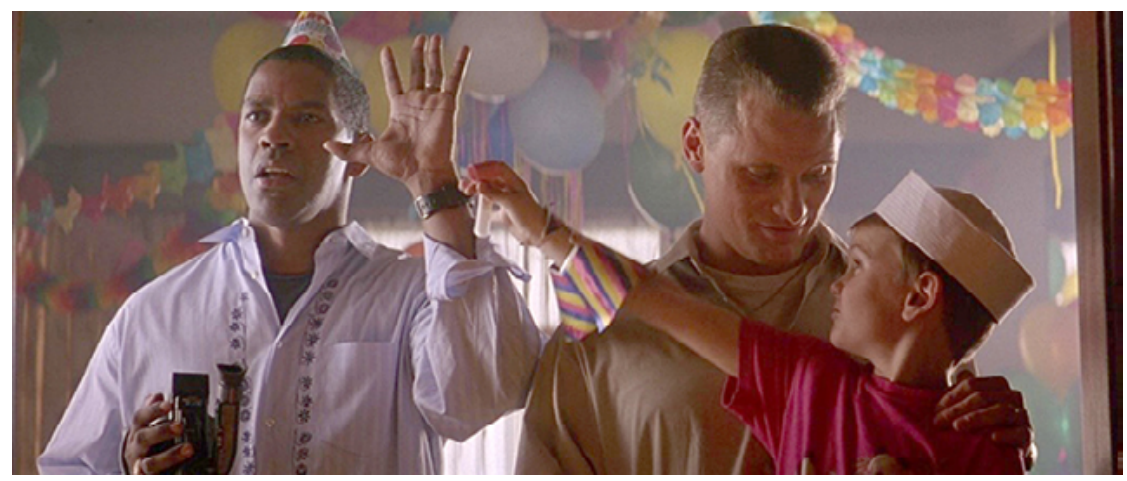

Fig. 15. Hunter y «WEPS» durante la escena de la fiesta de cumpleaños. Crimson Tide (Tony Scott, 1995). Hollywood Pictures y Don Simpson / Jerry Bruckheimer Films.

\subsection{CONCILIO Y REDENCIÓN}

El comandante Richardson es testigo de su propia caída en Run Silent Run Deep, pero, finalmente, consigue su objetivo gracias al entendimiento con Bledsoe, que se apropia de la determinación de su capitán tras sobrevivir al ataque enemigo y al detectar posibilidades de éxito en el contraataque. De esta manera, la superación del antagonismo entre ambos se soluciona a través de un sentimiento compartido por eliminar al agresor. Richardson, correspondiendo a la dinámica de relación paternal y edípica entre ambos, reconoce en privado al primer oficial que confiaba en su valentía: «tuve el presentimiento de que su orden de retirada no llegaría a cumplirse».

De esta manera, Richardson resulta ser un inesperado maestro para el primer oficial, y este aprenderá el valor de la convicción y el arrojo de su superior. Tras la muerte del comandante, una vez proclamado líder del Nerka, Bledsoe es el apoderado para consolidar a Richardson como honorable frente a la tripulación. El nuevo comandante dirige un acto militar de sepultura en el mar y completa de esta manera su licencia para gobernar en solitario, asimilando para sí la lección del comando que Richardson le legó en vida. Durante el acto, Bledsoe lo reconoce mediante un saludo militar por primera y última vez en el momento en que el cuerpo de comandante es enviado a las profundidades del océano ${ }^{29}$.

Para el caso de la película de Scott, el comandante Ramsey es derrotado sin paliativos por la razón de Hunter acerca del mensaje incompleto sobre el disparo de la fuerza nuclear. La tripulación al completo es informada por el propio comandante del contenido de la orden y en ese instante cesa la lucha por el control del Alabama.

29 De igual modo que los restos de Richardson, el comandante Ramsey abandona el microcosmos del submarino mediante un acto de descenso. 


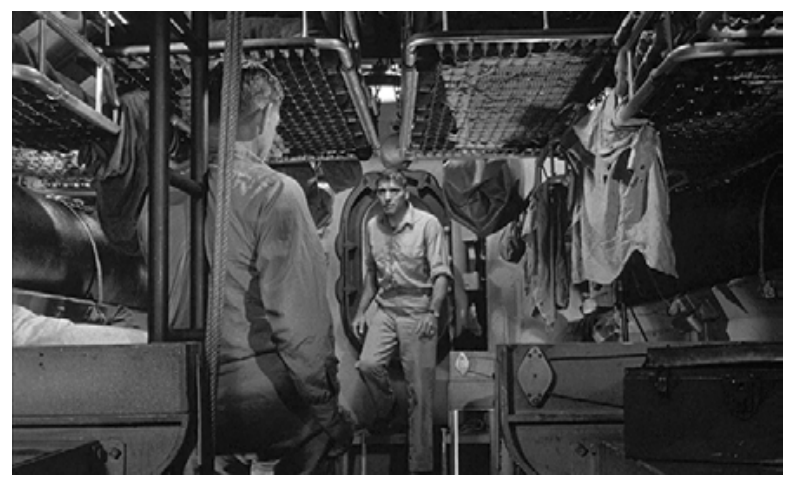

Fig. 16. En último acto de Run Silent, Run Deep, Richardson y Bledsoe acercan posiciones. Run Silent Run Deep (Robert Wise, 1958). Hill-Hecht-Lancaster Productions y Jeffrey Pictures Corp.

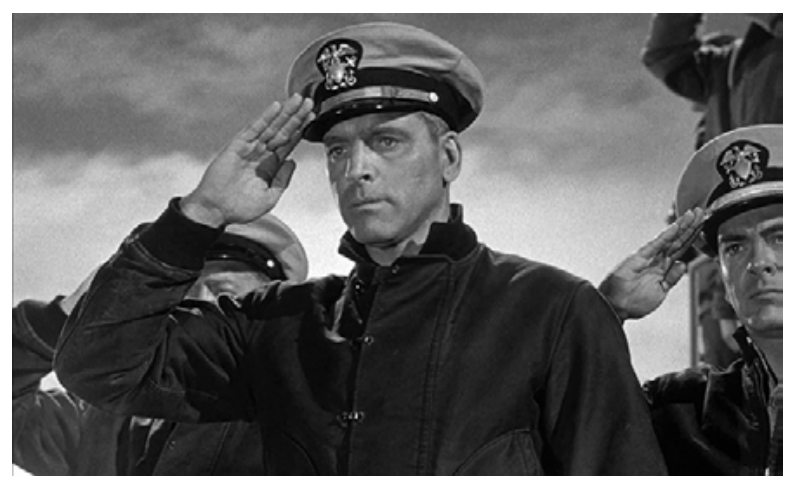

Fig. 17. El nuevo comandante del Nerka despide el cuerpo de Richardson en alta mar. Run Silent Run Deep (Robert Wise, 1958). Hecht-Hill-Lancaster Productions.

A continuación, Ramsey cede el gobierno a su primer oficial para convertirse en un actor irrelevante en el navío.

Como se ha descrito anteriormente, resulta habitual en estos relatos que el cisma del comando se repare al llegar a la conclusión, exhibiendo una buena imagen de la Marina. Este no es el caso de Crimson Tide, quizás el único filme de guerra submarina en el que el comando no llega nunca a resarcir su división (Rayner 2007: 190). Este hecho es remarcado durante la escena de la junta de investigación, donde no se determina una parte como la acertada: «extraoficialmente ambos crearon un lío tremendo. [...] la violación del protocolo de lanzamiento nuclear» ${ }^{30}$.

${ }^{30}$ La exaltación de patriotismo épico durante la escena en la que Ramsey se dirige a su tripulación antes de zarpar el Alabama queda soslayada por la problemática expuesta durante la investigación. 


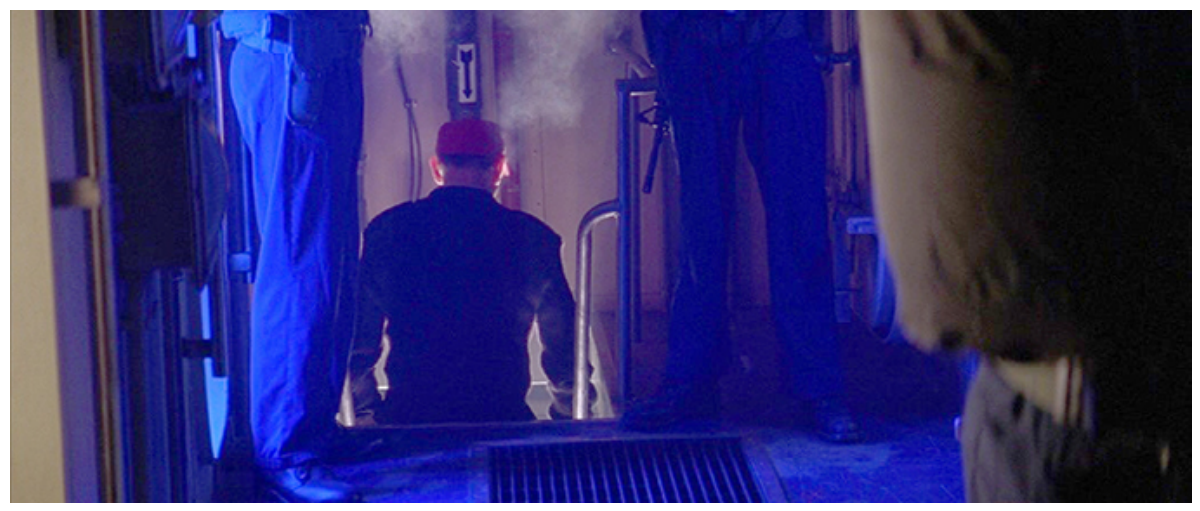

Fig. 18. Ramsey abandona la sala de control del Alabama en un simbólico descenso hacia su cese. Crimson Tide (Tony Scott, 1995). Hollywood Pictures y Don Simpson / Jerry Bruckheimer Films.

A nivel personal, sí se alcanza cierta conciliación en el epílogo de Crimson Tide. Ramsey recomienda a Hunter para ser ascendido a comandante frente al comité investigador ${ }^{31}$ y poco después ambos protagonizan la última escena de la película. El momento está localizado en un soleado espacio exterior, la antítesis del entorno de presión que ha contextualizado todos sus enfrentamientos. Los dos marinos visten uniforme durante la escena, lo que aporta un carácter oficial al encuentro. Hunter da el primer paso para agradecer la intercesión del comandante a su favor: «solo quería darle las gracias», y desciende unas simbólicas escaleras que separan a ambos con la complicidad de la cámara sobre grúa de Tony Scott. Ramsey, a continuación, bromea sobre todo lo ocurrido retomando la primera conversación durante su «entrevista-enlace», y durante el último asalto al poder dentro del Alabama: «usted tenía razón y yo me equivoqué [...] sobre los lipizzanos, son de España y no de Portugal». Hunter responde con una sonrisa irónica, para acto seguido cerrar el encuentro con un saludo militar. Al igual que Run Silent Run Deep, el saludo es símbolo de respeto, pero también anuncia una separación definitiva. Se trata de la despedida de dos hombres con principios opuestos que reconocen una consideración mutua, al mismo tiempo que ratifican como irreconciliable su punto de vista sobre el incidente. Para el espectador, Ramsey ya no se percibe como un villano y el personaje se redime al reconocer el valor y méritos de Hunter.

31 Se consuma la teoría de «impugnación al padre» o «matar al padre» propuesta por Rayner como ejercicio final al acceso del comando por parte del primer oficial. Ello implica en Crimson Tide la jubilación del comandante Ramsey y una tendencia «paternalista» por su parte al reconocer y promover los méritos de Hunter. 

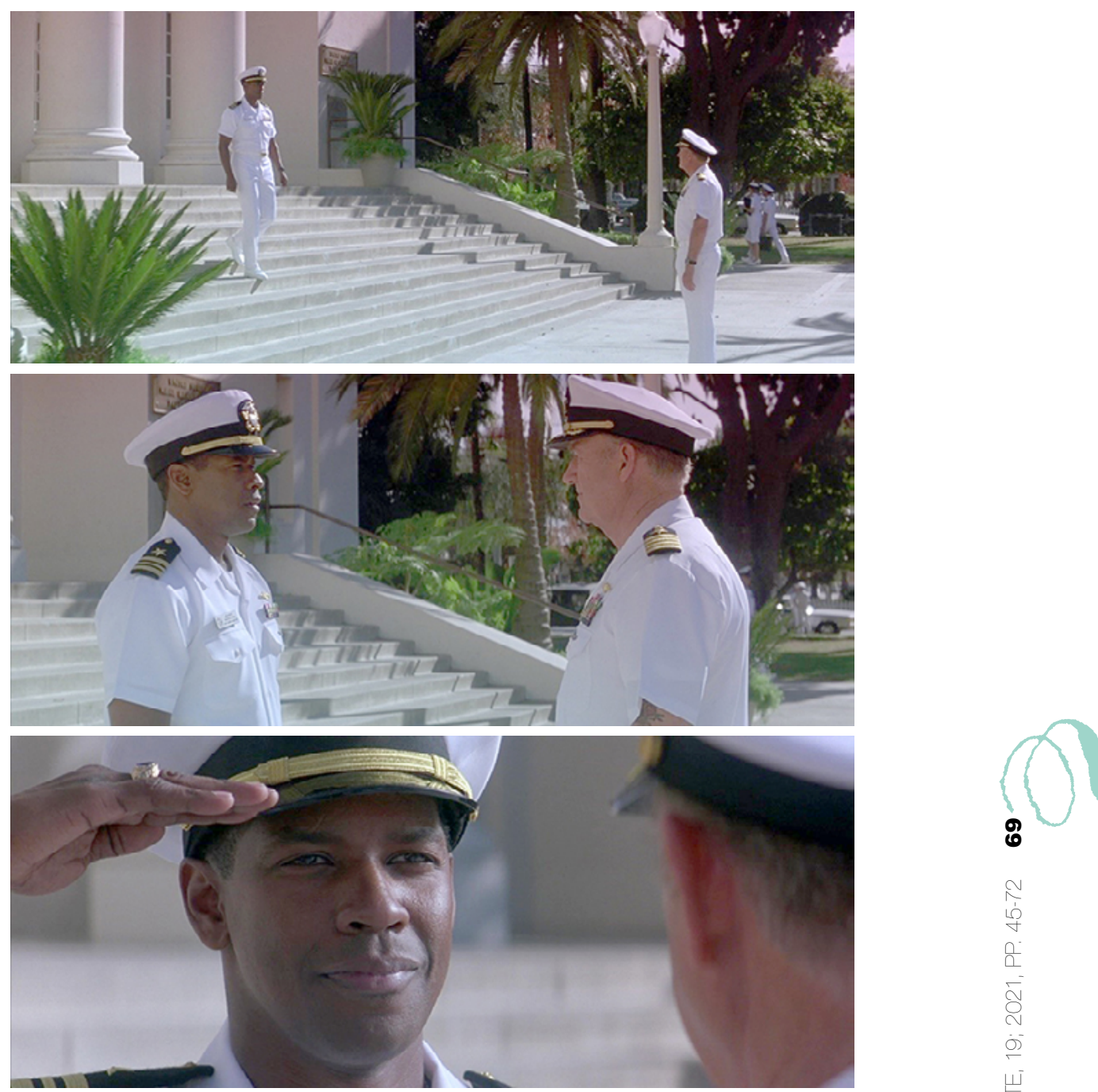

Fig. 19. Secuencia de fotogramas de la última escena de Crimson Tide (Tony Scott, 1995). Hollywood Pictures y Don Simpson / Jerry Bruckheimer Films.

\section{CONCLUSIONES}

Las dos películas estudiadas establecen la relación antagónica entre sus personajes protagonistas desde las primeras escenas que comparten en pantalla. El disentimiento motivado por conflicto ideológico o por disputa ya es manifiesto antes de las patrullas, para, a continuación, trasladarse al ejercicio de gobierno de las naves submarinas y agravarse en un entorno hostil, de confinamiento y en estado de guerra. En este sentido, la intensidad de estos incidentes se determina en gran parte por 
la capacidad destructiva que tiene cada buque según la hipótesis de Koldau. Para el caso de Crimson Tide, al ubicar la historia en un submarino estratégico nuclear con una capacidad de fuego inimaginable, se incrementa considerablemente el factor de desestabilización del comando.

En lo que concierne a la habitual restauración de la buena imagen de la Marina en la conclusión de las películas de guerra submarina norteamericanas con la temática de la crisis de comando, como ocurre en Run Silent Run Deep, puede observarse su opuesto en Crimson Tide. La película de Scott, a pesar de hacer gala de instantes de un patriotismo entusiasta, no resuelve nunca el fallo del comando respecto al uso del armamento nuclear y únicamente se alcanza un concilio satisfactorio a nivel personal. Por consiguiente, la Marina de los Estados Unidos no pudo revalidar la visión idealizada del arma submarina nuclear que esperaba a cambio de su cooperación, que finalmente no se llevó a cabo. A pesar la leyenda que aparece en pantalla en los créditos finales sobre la actualización del decreto respecto a la orden de disparo, el descrédito a la buena praxis en un submarino norteamericano nuclear visto en Crimson Tide queda patente y da pie a un debate antibelicista del que Run Silent, Run Deep carece.

La realidad de la guerra nuclear es un escenario que cambia la estrategia argumental de la crisis del comando en el cine de guerra submarina norteamericano. Al contrario de lo que ocurrió tras la Segunda Guerra Mundial, el cine producido en la era post Guerra Fría ya no es capaz de trasladar el modelo de relato sin consecuencias en su relación con las fuerzas armadas. No obstante, el atractivo comercial que supuso un duelo interpretativo de estrellas de cine de Hollywood demostró ser suficientemente sugerente para prescindir de la cooperación. Pese a ello, no se ha vuelto a estrenar una película norteamericana sobre la crisis del comando en submarino nuclear de la Marina de los Estados Unidos desde el año 1995. 


\section{REFERENCIAS}

Ferro, Marc. 1995. Historia contemporánea y cine. Madrid: Editorial Ariel.

Koldau, Linda M. 2012. Reprasentätionen des Krieges. Göttingen: Wallstein Verlag.

KoldAu, Linda M. 2011. «Why submarines? Interdisciplinary approaches to a cultural myth of war». Journal of War and Culture Studies 4: 65-78.

Ketov, Ryurik A. 2005. «The Cuban Missile Crisis as Seen Through a Periscope». Journal of Strategic Studies 28: 217-231.

Mata, Santiago. 2015. U-Boote. El Arma Submarina Alemana durante la Segunda Guerra Mundial. Madrid: La Esfera de los Libros. Edición Kindle.

McKee, Robert. 2002. El guión. Madrid: Alba Editorial.

Nichols, Bill. 2009. «Seven Reasons Why I Love Submarine Movies». The Velvet Light Trap 64:102103.

Rayner, Jonathan. 2007. The naval war film. Manchester: Manchester University Press.

Roвв, David. 2004. Operation Hollywood: How the Pentagon Shapes and Censors the Movies. New York: Prometheus Books.

Rodríguez, Hilario J. 2006. El cine bélico. Barcelona: Ediciones Paidós Ibérica.

Rosentone, Robert A. 1988. «La historia en imágenes/la historia en palabras». The American Historical Review 93: 1174.

Rowan, Terry. 2012. World War II Goes to the Movies \& Television Guide, volume II, L-Z. Morrisville: Lulu Press Inc.

Suid, Lawrence. 2002. Guts \& Glory: The Making of the American Military Image in Film. Lexington: University Press of Kentucky.

Box Office Mojo. 2020. «Crimson Tide». Consultado el 16 de diciembre de 2020. https://www. boxofficemojo.com/title/tt0112740/?ref_=bo_rl_ti.

Box Office Mojo. 2020. «The Hunt for the Red October». Consultado el 8 de diciembre de 2020. https://www.boxofficemojo.com/title/tt0099810/?ref_=bo_se_r_1.

Cinema Blend. 2009. «Interview: Tony Scott». Consultado el 28 de diciembre de 2020. https:// www.cinemablend.com/new/Interview-Tony-Scott-13537.html.

LA RAZÓN. 2019. «Escándalo en un submarino nuclear de EE. UU.: tripulantes confeccionan una lista de violación». La Razón, 18 de mayo de 2019. Consultado el 10 de octubre de 2020. https://www.larazon.es/internacional/escandalo-en-un-submarino-nuclear-de-ee-uu-tripulantes-confeccionan-una-lista-de-violacion-HK23388078/.

Institute of International Studies, UC Berkeley. 1998. «The Wise Touch. Conversations with Robert Wise». Consultado el 4 de diciembre de 2020. http://globetrotter.berkeley.edu/conversations/Wise/wise-con5.html.

Internet Movie Database. 2021. "Quentin Tarantino». Consultado el 14 de enero de 2021. https:// www.imdb.com/name/nm0000233/?ref_=nv_sr_srsg_0.

Internet Movie Database. 2021. «Sort by Popularity - Most Popular Movies and TV Shows tagged with keyword submarine-movie». Consultado el 11 de enero de 2021. https://www. imdb.com/search/keyword/?keywords=submarine-movie. 
Lantern. 2021. «Motion Picture Daily. UA’s Relases Oct-Dec 1958». Consultado el 18 de enero de 2021. https://lantern.mediahist.org/catalog/motionpicturedai84unse_0_0046.

Ryan, Tim. 1995. «Navy wasn't privy to 'Tide'». Reading Eagle, 12 de mayo. Consultado el 3 de enero de 2021. https://news.google.com/newspapers?nid=1955\&dat=19950512\&id=WxkyAAAAIBAJ\&sjid=D6IFAAAAIBAJ\&pg=3632,6592013.

Submarine Force Pacific. 2020. «USS Alabama SSBN 731». Consultado el 26 de noviembrede 2020. https://www.csp.navy.mil/alabama/About/. 